\title{
Erratum to: Wild pistachio tree (Pistacia mutica) in the Qalajeh forest region of western Iran
}

Mohsen Javanmiri Pour • Mousa Rasouli • Hamid Soofi Mariv

Mohammad Avatefi Hemat • Masood Shahmoradi

(C) Northeast Forestry University and Springer-Verlag Berlin Heidelberg 2014

Erratum to: Journal of Forestry Research, (2013) 24(3): $611-614$

DOI 10.1007/s11676-013-0393-2

The original version of this article unfortunately contained one mistake in author name in the footnote. The second author's name,

"Mousa Rasouli", actually should be Hamid Soofi Mariv. The corrected version of the footnote should be as the following:

The online version of the original article can be found at

http://dx.doi.org/ 10.1007/s11596-013-1182-z

Mohsen Javanmiri Pour ( $(\underline{\underline{a}}) \cdot$ Hamid Soofi Mariv $\bullet$ Mohammad

Avatefi Hemmat

Natural Resource Faculty, Tehran University, Karaj, Iran.

E-mail: Mjavanmiri@live.com

Mousa Rasouli

Landscape Engineering Department, Faculty of Natural Resources and

Environment, Malayer University, Malayer, Iran.

Masood Shahmoradi

Department of Horticulture Science, Agriculture Faculty, Guilan

University, Rasht, Iran.

Corresponding editor: Zhu Hong 